REVIEW

\title{
Exploration of the Research-Based "New Basic Education” Experiment by Lan Ye
}

\author{
Weijie Meng, Fengqi Ning \\ Nanjing Yutong Experimental School, Nanjing 211100, China
}

\begin{abstract}
New Basic Education" as a localized strategy in China was produced during the social transformation. It aims to stimulate the internal development motivation of schools, principals, and teachers and promote the upgrading and transformation of classrooms and schools. To get through theory and practice connection, taking root in schools, doing "ground-based" research, and exploring a new path for the ecological growth of regional school groups. Starting from the background of the "new basic education" research, this paper elaborates the content, history, ideological system, and influence. It hopes to provide a more comprehensive and objective overview of the "new basic education" research to inspire most educators. Help everyone explore the practical way to improve the quality of education.

Best Evidence in Chinese Education 2021; 8(2):1121-1130.

Doi: 10.15354/bece.21.re048.

How to Cite: Meng, W., \& Ning, F. (2021). Exploration of the research-based "New Basic Education" experiment by Lan Ye. Best Evidence in Chinese Education, 8(2):1121-1130.
\end{abstract}

Keywords: "New Basic Education", Research Content, Research Process, Research Thought, Overview

\footnotetext{
About the Author: Weijie Meng, Principal of Nanjing Yutong Experimental School, 22 Jiangjun Avenue, Jiangning District, Nanjing City, Jiangsu, China 211100.E-mail: 13608955415@126.com

Correspondence to: Fengqi Ning, Nanjing Yutong Experimental School, 22 Jiangjun Avenue, Jiangning District, Nanjing City, Jiangsu, China 211100.E-mail:872225979@qq.com

Conflict of Interests: None.
}

(C) 2021 Insights Publisher. All rights reserved.

Creative Commons Non Commercial CC BY-NC: This article is distributed under the terms of the Creative Commons Attribution-NonCommercial 4.0 License (http://www.creativecommons.org/licenses/by$\mathrm{nc} / 4.0 /$ ) which permits non-commercial use, reproduction and distribution of the work without further permission provided the original work is attributed by the Insights Publisher. 


\section{Background of "New Basic Education"}

$\mathrm{F}$

TROM a historical perspective, whenever society underwent a significant transformation, people's criticism of education often started from value criticism, from a re-recognition of the value and purpose of education, and using this as the basis and starting point then to realistic educational activities. Eventually, they made a more specific evaluation and proposed new principles, plans, and methods (Ye, 2002).

From the end of the 20th century to the beginning of the 21 st century, China was in a particular period of social development and transformation, and its spirit of the times had the characteristics of "focusing on the future, emphasizing development, and basing on change." At the same time, genuine reform had brought about the inherent need of "focusing on choice" and "calling people's subjective spirit (Ye, 2006A). In the early 1980s, Lan Ye was engaged in basic theoretical research on pedagogy, and she felt that our pedagogical thinking was rigid and the conclusions were too simple. What's more serious was that there were no real people or only "one-sided" people in pedagogy. We only studied how to teach people to understand the outside world and forgot that the most important half is how to make people learn to know and develop themselves. In 1994, Professor Ye once again went deep into reality and believed that the metaphysical understanding of the existence and development of human life in education should not treat students as things and should not treat students differently. It was necessary to regard the enhancement of people's consciousness of life as the important provisions of the times on education. She started the research on "new basic education" (Li, 2004). Her research aimed to create a new type of primary education that conforms to China's spirit. The study of contemporary development and changes in Chinese society made a big impact on school education reforms.

At the same time, China launched the eighth basic education curriculum reform. $\underline{I}$ This "curriculum reform" clearly proposed the "new curriculum reform." It can be said that the "new" in the "new basic education" is a response to this "new curriculum reform," and it is also a discussion and practice of contemporary Chinese social development and educational values reform (Ye, 1994).

\section{Research Content of "New Basic Education"}

The research content of "new basic education" includes two aspects: theory and practice. These two aspects are intertwined and grow together in the process of research. In the research and exploration stage, a moderately leading theory and close integration of theory and practice were proposed. The research process has evolved into promoting the experimental research results of the "new basic education," continuously researching the combination of theory and practice. Therefore, the main contents of developmental research are as follows:

\section{The Background and Overall Research of School's Transformational Change}


The developmental research of "New Basic Education" is dedicated to revealing the internal relationship between social transformation and school transformation, revealing the fundamental aspects of school transformation and the essential characteristics of new schools, as well as the basic strategies and paths to achieve school transformation, and then forming the theory of "school transformation." In this sense, it can be said that the "new basic education" theory is a theory of educational change about school transformation (Ye, 2004).

\section{The Basic Theory and Practice Update in the School's Transformational Reform}

In the stage of exploratory research, through a critical analysis of the problems in school education and their causes, the theoretical discussion was focused on the renewal of the educational concept system, the renewal of the school education training target system, and the renewal of the basic activities of school education (Ye, 1999). On the one hand, developmental research strengthens the theoretical research on the reform of school management and the academic research on the development of teachers and students in the "dual transformation" of contemporary society and schools to form a relatively complete "new basic education" theory. At the same time, it has strengthened the basic issues of a series of educational theories involved in the "new basic education" and updated research on school training goals, classroom teaching, class construction, teacher development, school management evaluation, and other aspects.

\section{Systematic and In-Depth Study of the Teaching Reform of Basic Subjects in Elementary and Middle Schools}

The "New Basic Education" experiment has researched the teaching reform of three basic Chinese, mathematics, and foreign languages in primary and middle schools and has expanded in-depth systematization and application. It enables the theory of classroom teaching reform in the "new basic education" to be embodied in the teaching reform theory of significant disciplines. It also enriches and develops with the help of theoretical research on teaching reform of marked fields. At the same time, it also has a pivotal role in the teaching reform practice of experimental schools (Ye \& Wu, 2004).

\section{Methodological Research on the Path and Strategy of School Transformational Change Research, Educa- tional Theory, and Educational Practice}

In the research and development process of "New Basic Education," on the one hand, breakthroughs have been made in the understanding of the relationship between educational theory and practice. On the other hand, the research also reflects the richness of the relationship between academic theory and educational training. Researchers deeply 
feel that the multiple and rich connections between educational theory and educational practice are an essential issue that cannot be avoided in the development of pedagogy and educational practice in contemporary China. It is a reflective issue of academic research itself and belongs to scholarly research. It is also a methodological study of "New Basic Education" as a research project.

\section{"New Basic Education" Research History}

The "new basic education" reform can be roughly divided into five internally connected development stages. They are the exploratory research stage, the developmental research stage, the shaping research stage, the grounded research stage, and the ecological research stage.

\section{Exploratory Research Stage (September 1994- September 1999)}

In the early 1990s, after conducting a series of in-depth reflections and theoretical constructions on basic education, Lan Ye began to turn his research perspective to the field of basic education practice. At the beginning of the study, Professor Ye and several other researchers from East China Normal University discussed Shanghai Wai Gao Qiao Free Trade Zone Experimental Elementary School Guodong Chen and vice-principal $\mathrm{Yu}$ Zhang to carry out a voluntary collaborative study. In the pilot research stage, the research team members determined the research plan on the one hand. They proposed the basic theoretical concept system ("Three Views and Ten Characteristics") ${ }^{2}$ related to the overall reform of contemporary school education. Under the existing conditions, carry out limited basic research (Ye, 2006B).

At this stage, the breakthrough was to change the original classroom teaching pattern of "teacher speaks for words, and a few good students play the leading role." The "time," "space," "tools," "right to question," and "right to comment" were returned to students to form a new classroom space-time structure. Structural adjustments were made to the teaching content, and a "teaching structure" was proposed in the classroom so that students could learn to "use the structure," forming a "long-term two-stage teaching."

In 1997, the "New Basic Education" research was approved as the National Educational Science "Ninth Five-Year Plan" project of the Ministry of Education. Since then, the "New Basic Education" experiment began to be studied in a broader range. By 2000, there were 55 core experimental schools in Chongming County, Shanghai, and more than 200 schools were radiated.

In May 1999, Shanghai New Basic Education Research Institute was established. In the same year, the "Developmental and Promotional Research on New Basic Education" was officially launched. 


\section{Developmental Research Stage (September 1999-May 2004)}

When the developmental research on "new basic education" started in September 1999, it did not establish a project in the country. The study was carried out by the East China Normal University project team, 17 schools in Minhang District, and four schools in Chongming County. In the past five years, since inheriting the original experience, the research team members have developed and deepened the systematic research of the school change theory. From the core of research and its impact on practice, the "new basic education" still focuses on classroom teaching (Ye, 2004), forming a series of new indicators for teaching evaluation, guiding teachers' teaching design, teaching process, and teaching reflection.

In addition, during this period, the research was extended to many provinces and cities in coastal areas and received support from relevant regional leaders. The East China Normal University research team members traveled to pilot schools and regions every semester, and pilot schools were held in an area every semester. In the exchange seminars, the research tradition of the "new basic education" community has been formed.

In May 2004, the "New Basic Education" theory and the promotion and developmental research topic problem-solving conference were held in Shanghai, and at the same time, it hosted a nationwide on-site seminar. "Developmental research" results were reflected in a series of "new basic education" developmental research books edited by Lan Ye.

\section{Shaping Research Stage (June 2004-June 2009)}

This stage is where the "new basic education" research begins to reflect and refine the theory and practice. The focus of research has been shifted from "classroom" to "basic education reform and overall school transformational reform."

The research team has done research and practice in the school leadership to improve leadership team reform, such as institutional reform, system reform, leadership concept system update, and overall school reform planning, and deepen the reform of the teaching system based on disciplines. At the same time, the research team has also strengthened the evaluation research and "checking" each experimental school by grade to promote the involvement of more teachers in deepening research (Ye, 2020). On this basis, the "Guidelines for Teaching Reform of Subjects" such as Chinese, Mathematics and English are refined to realize the systematic structure of rich, original experience and typical cases in the daily teaching reform research of "New Basic Education."

In May 2009, the "New Basic Education" Formability Research Achievement Release and On-site Seminar were held in Shanghai. The "New Basic Education" Shaping Research Series was launched at the conference.

\section{Grounded Research Phase (October 2009-May 2012)}


The notable changes in the research subject, research methods, and research horizons of the research in the formability stage have activated the initiative and creativity of each school in the symbiote. Some schools have created typical experiences in different fields and achieved significant development results. Grounded research is a test of whether the "new basic education" system theory can bring about the accelerated development and high-quality completion of the school after its formation.

Therefore, the main research task is to transform the current results into the daily education and teaching research process through "forward and follow-up" discussions, become the conscious change of behavior of principals and teachers, and extend it to all disciplines. Model research and quality courses are the carriers to deepen and improve the research results, making this achievement rooted in every teacher, every school, and every regional action.

In May 2012, 9 "new basic education" base schools were selected as the first batch of "life-practice" pedagogy cooperative research schools.

\section{Ecological Research Stage (2012-Present)}

Since 2011, the Minhang District of Shanghai took the lead in carrying out the "New Basic Education" ecological zone research; four regions across the country (Shanghai, Changzhou, Huaiyin, and Qingdao) have formed 14 ecological groups of varying sizes and numbers. All participating schools are jointly developed to create a "new basic education" ecological national symbiosis. Therefore, at this stage, research is no longer taking a school and an area as an environmental area, but with the cultivated cooperative schools as the core, forming a permanent leader school, a rotating leader school, and a backbone school, etc. The echelon development pattern of the ecological zone in China and promote the reform results. At the same time, through ecological activities, local teaching and research forces in experimental schools and regions have been cultivated. In Minhang District, Shanghai, 256 principals, and teachers have become parttime researchers and formed the district's evaluation team.

In May 2018, at the 10th National Symbiosis Conference of "New Basic Education," Professor Lan Ye reported on the theme of "Research on 'New Basic Education' in the New Era," re-establishing the "life-practice" pedagogy The highest goal of education-"naturally." Under its influence, this research has continued to this day.

\section{"New Basic Education" Theoretical System Construc- tion}

\section{The Construction of New Basic Education Values}

Education has the role of guiding the value of life. It gives students correct life guidance, builds a pillar of the spiritual level of students, and lays a foundation for students' knowledge, ability, and moral foundation. At the same time, it should also cultivate students' living abilities, communication skills, etc., and comprehensively improve stu- 
dents' abilities. It teaches students to love life, study, and work and helps students establish a positive and healthy life goal.

Under the view of life education, education should focus on students' spiritual growth and then impart knowledge to students. Therefore, the value of the new basic education must be reflected in people's knowledge level and based on people's life development and promote the comprehensive development of students' moral, intellectual, physical, aesthetic, and labor. The comprehensive sublimation from knowledge education to emotional education can cultivate people who meet the needs of modern values (“New Educational Experiment” research group, \& Zhang, 2006).

\section{The Construction of the Value of Students in New Basic Education}

The concept of students constructed in the new basic education is as follows: First, respect for students' differences in education is the primary criterion, proceed from reality, and teach students by their aptitude. Use a unified educational mechanism and model to be applied to students with individual differences in a targeted manner. Second, attach importance to the cultivation of students' initiative and constantly cultivate students' active learning ability to change from passive to active. At the same time, students must be able to think deeply, be strong, optimistic, and have a positive attitude. Third, fully tap the students' potential and let them realize their unlimited potential (Wang, 2018).

\section{The Construction of the Value of Teachers in New Basic Education}

The concept of teachers constructed in the new basic education is: First, clearly recognize the role of teachers, emphasize the meaning and value of teachers' lives, respect teachers and their labor. At the same time, we must respect our development, enhance our spiritual needs, and work for education to provide an excellent educational or research environment and academic funding support. Second, pay attention to teachers' differences, point out teachers' education mistakes, correct them to educate students correctly, mobilize teachers' educational significance with the most incredible enthusiasm, and respect each life and individual with a broad mind.

\section{The Construction of Curriculum Value in New Basic Education}

The main goal of education and teaching is curriculum education. The curriculum is the foundation of students' learning, the key to students' mastery of skills, and the carrier of students' knowledge and shaping their character. Therefore, the rationality of curriculum design is the key to education. The curriculum concept of the new basic education construction is as follows: First, the content of the curriculum should be expanded with theory, theory combined with practice, academic integration with life, and natural inte- 
gration with humanities. It is necessary to teach students professional knowledge and skills and to broaden students' horizons. Second, set up a reasonable curriculum structure, strengthen the comprehensive curriculum, expand students' thinking ability and thinking ability, deeply tap students' learning potential, encourage students' innovative spirit, observe the details of daily life, and integrate life into the curriculum. Life is the source of knowledge (Ye, 2002).

\section{The Construction of the Teaching Value in New Basic Education}

Compared with the traditional teaching process where the teacher is the instructor, and the student is only the role setting of the learner, the new basic education emphasizes the teacher's teaching ability, teaching initiative, and teaching advancement. Teaching activities, "teaching" and "learning" must be integrated and cannot be carried out independently. Teachers and students should incorporate into each other's roles. Teachers should interact with students in the classroom, cultivate mutual understanding, learn from each other, complement each other, enhance and promote each other, teachers and students grow together.

The overall teaching process is necessary to strengthen the teacher-student interaction and stimulate teachers' and students' creativity. The teaching concept of the new basic education construction is: First, the primary task of education is to "put people first" and change the traditional view of "emphasis on cognition and light of emotion" and "emphasis on education and education." The new basic education should emphasize emotion and pay attention to experience life, the formation of students' good morals, and the cultivation of personality. Second, change the viewpoint of imparting knowledge from passive to active. Transform "Teaching knowledge to students" into "Guiding students to learn knowledge." As a result, traditional teaching methods are transformed into valuable teaching methods so that students can experience a meaningful learning state (Zhao, 2009).

\section{The Impact of "New Basic Education" Research}

From the exploratory research in the 1990s to the extensional and developmental research in the first five years of the twentieth century, to the subsequent shaping research, the "new basic education" has always focused on the social and educational issues in the transitional period of China. From the classroom and class level to the school level, the theory and logic continue to advance, and the research and practice continue to expand. Through a comprehensive reflection on traditional school education, the theoretical and practical concept of "new basic education" was put forward, leading the trend of basic education research and practice in China at the turn of the century, and directly spawning China's first localized education school, namely "Life-Practical Education School," a feasible way for China's educational innovation (Ji \& Shen, 2009).

The theoretical and practical research on the "new basic education" initiated and led by Professor Lan Ye still attracts most elementary and middle schools. It is re- 
ported that the new basic education has been deeply involved in the education and teaching reform of more than 200 schools in 12 provinces and cities, including Shanghai, Beijing, Jiangsu, Zhejiang, Shandong, and Henan, and has driven more than 3,000 teachers and tens of thousands of students to conduct research together. It has had a wide range of influences at home and abroad (Wang, 2019).

However, we must also see that the "new basic education" research is not strictly rigorous evidence-based research in education. Compared with similar foreign studies, such as the "Success for All" reform of American schools carried out by American scholar Robert Slavin and others, the "new basic education" research mainly focuses on observation method, conversation method, and case method. Less use of test methods, experimental methods, etc., which is essentially more similar to the promotion and practice of a teaching method and idea, leading to some conclusions of its research is also open to question.

\section{Notes}

1. China's new round of basic education curriculum reform was officially launched in 1999. From January to June 2000, the development group of curriculum standards for various disciplines was established through the application and review. From July 2000 to February 2001, each development group formed the first draft of the curriculum standard based on unique research. In March 2021, the Department of Basic Education of the Ministry of Education will solicit opinions from educators, experts, and scholars in 9 regions to revise the curriculum standards of various subjects further. In July, the Ministry of Education promulgated the "Basic Education Curriculum Reform Outline (Trial)." A few days ago, the national curriculum standards covering 18 subjects of compulsory education in elementary and middle schools had been developed and entered the basic education curriculum reform experimental area on September 1. The new round of basic education curriculum reform will promote the comprehensive implementation of quality education in basic education, objectives, and content. The new curriculum reform has continued to this day.

2. Lan Ye et al. proposed in 1999 that it refers to the future, vitality, and sociality of basic education in values; the initiative, potential, and difference of students in the view of students; the bilateral synchronicity of educational activities in the opinion of school educational activities Flexible structure, dynamic generation, and comprehensive permeability.

\section{References}

Ji, L., \& Shen, Z. (2009). "New Basic Education" 15 -year research results released. China Education News, 05-18-2009. [Chinese] DOI: https://doi.org/10.28102/n.cnki.ncjyb.2009.0 03754

Li, Z. (2004). Pursuing the Educational Wisdom of "Life•Practice"-Lan Ye and "New Basic 
Meng \& Ning. Research-Based "New Basic Education" Experiment by Lan Ye.

Education." Primary and Middle school

Management, 18(4):22-26. [Chinese] DOI:

https://doi.org/10.3969/j.issn.1673-

$\underline{4289.2004 .06 .026}$

Liu, D. (2003). The voice of the era of China's basic education reform-Lan Ye's thoughts on basic education reform. Educational Science Research, 14(6):9-12. [Chinese]

https://www.cnki.com.cn/Article/CJFD2003JYKY200306002.htm

Wang, W. (2018). The connotation and pursuit of the new basic education theory. Teacher, 12(35): 46-47. [Chinese]

http://www.cnki.com.cn/Article/CJFDTotalJAOS201835023.htm

Wang, Y. (2019, December 19). What has changed in the "New Basic Education" in 20 years. China Youth Daily. March 20, 2021. Retrieved from https://baijiahao.baidu.com/s?id=165335665 $9616456476 \& w f r=$ spider $\&$ for $=p c$

Ye, L. (1994). The spirit of the times and the construction of new educational ideals-A cross-century reflection on the reform of basic education in my country. Educational Research, 1(10):3-8. [Chinese] http://www.cqvip.com/qk/96925x/199410/1 003301541.html

Ye, L. (1999). Collection of exploratory research reports on "New Basic Education." Shanghai: SDX Joint Publishing Company.

Ye, L. (2002). Rebuilding classroom teaching values. Educational Research, 9(5):3-7+16. [Chinese] DOI:

https://doi.org/10.3969/j.issn.10047549.2003.02.005
Ye, L. (2004). "New Basic Education" Developmental Research Report Collection. Beijing: China Light Industry Press.

Ye, L. (2006A). Some thoughts were arising from the study of "New Basic Education." People's Education, 57(7):4-7. [Chinese] https://www.cnki.com.cn/Article/CJFDTotal -RMJY200607002.htm

Ye, L. (2006B) Theory of "New Basic Education"-Inquiry and Understanding of Contemporary Chinese School Reform. Beijing: Education Science Press

Ye, L. (2020). Unforgettable 25 years of life. My thoughts on the uniqueness of "new basic education" research. Shanghai Education, 27(31): 40-41. [Chinese] http://hyxx.zledu.com/photos/201409/82_20 140924092516187.doc

Ye, L., \& Wu, Y. (2004). Reform of classroom teaching and classroom teaching evaluation reform. Liaoning Education, 11(3):39-39. [Chinese]

http://www.cnki.com.cn/Article/CJFDTotalLNJY200403022.htm

Zhang, R. (2006). The basic theory and practical exploration of "New Educational Experiments"-The final report of "The Practice and Promotion of New Educational Theory" (Part 1). Principal's Reading Magazine, 3(3):17-23. [Chinese] http://www.cnki.com.cn/Article/CJFDTotalXZRK200603007.htm

Zhao, H. (2009). Lan Ye's Basic Education Reform Thoughts. Shanghai Education, 16(Z2):96-97. [Chinese] https://www.cnki.com.cn/Article/CJFDTotal -SHJZ2009Z2096.htm 